\title{
Psychiatrists' Understanding and Management of Conversion Disorder: A Bi-National Survey and Comparison with Neurologists
}

This article was published in the following Dove Press journal:

Neuropsychiatric Disease and Treatment

\author{
Benjamin Dent ${ }^{\prime}$ \\ Biba R Stanton ${ }^{2-4}$ \\ Richard A Kanaan (iD) 1,4 \\ 'Department of Psychiatry, University of \\ Melbourne, Austin Health, Heidelberg, \\ VIC, Australia; ${ }^{2}$ Department of \\ Neurology, King's College Hospital, \\ London, UK; ${ }^{3}$ Department of \\ Neuropsychiatry, South London \& \\ Maudsley NHS Trust, London, UK; \\ ${ }^{4}$ Institute of Psychiatry, Psychology and \\ Neurosciences, King's College London, \\ London, UK
}

Background: A 2011 survey of neurologists' attitudes to conversion disorder found a tacit acceptance of the psychological model but significant ambivalence around its relationship to feigning. These issues are under increased scrutiny as the DSM-5 revision removed both the requirement for a psychological formulation and the exclusion of feigning from the diagnostic criteria. Whether those attitudes are shared with psychiatrists is unknown.

Methods: An online survey of the Section of Neuropsychiatry, Royal Australian and New Zealand College of Psychiatrists, and the Faculty of Neuropsychiatry, Royal College of Psychiatrists (UK), on their understanding and management of conversion disorder in February 2019. Statistical comparisons are made with our previous survey of Neurologists. Results: A total of 52 Australian and 131 UK-based members completed the survey which revealed similarities but also clear differences from their neurological colleagues. The psychiatrists strongly endorsed a psychogenic model for conversion disorder, and the conversion model in particular, though many models were employed. They felt a psychiatric assessment was essential to the diagnosis of conversion disorder, and they often disagreed with the diagnosis in neurology referrals of putative conversion disorder. Most felt that a psychiatric formulation was supportive, and many that it was necessary to the diagnosis. They saw feigning as usually present to a degree but were more comfortable with discussing this than neurologists.

Conclusion: Psychiatrists use psychosocial models for conversion disorder and see an overlap with feigning. They believe psychiatrists are essential for the diagnostic process and would not usually support a diagnosis without a psychiatric formulation.

Keywords: conversion disorder, functional neurological disorder, neuropsychiatrist, attitudes, feigning

\section{Introduction}

Conversion disorder has long been a controversial disorder for clinicians. ${ }^{1}$ It is traditionally conceived as a psychogenic reaction, ${ }^{2}$ yet it is diagnosed and managed largely by neurologists, who usually feel this is outside of their skill set. ${ }^{3}$ Neurologists are also unsure of the relationship of conversion disorder with feigning, perhaps as a result of their diagnostic approach, which has classically emphasised diagnostic "tricks". 4 We conducted a survey of neurologists on their attitudes to understanding and managing the disorder, ${ }^{5}$ which confirmed these impressions: though they accepted psychological models, they were uncomfortable in applying them, and there was considerable overlap with their concept of feigning.
Correspondence: Richard A Kanaan Department of Psychiatry,

Austin Health, LTBI0, I45 Studley Road, Heidelberg, VIC 3084, Australia

Tel +6I39496335I

Fax +6I39459082I

Email richard.kanaan@unimelb.edu.au
Neuropsychiatric Disease and Treatment 2020:16 1965-1974

1965

DovePress if in 
Furthermore, though the diagnostic process seemed to require two-steps and two-disciplines - neuropathology exclusion by a neurologist, followed by psychiatric formulation and the exclusion of feigning by a psychiatrist the neurologists often found psychiatrists unhelpful in this. ${ }^{6}$

In 2013, the 5th revision of $\mathrm{DSM}^{7}$ addressed these concerns: the criteria dropped the requirement for psychological formulation (the existence of a preceding stressor) and for the exclusion of feigning - and as the new criteria now rest primarily on the neurological evidence, the diagnosis can now be made by a neurologist alone. ${ }^{8}$ The 11 th revision of ICD, while its changes are less radical, also now includes some subtypes of conversion disorder in the neurology section. ${ }^{9}$

Perhaps surprisingly, given these changes, the attitudes of psychiatrists to this have not been systematically assessed. In particular, whether the attitudes and difficulties we identified in neurologists are unique to them or are shared by their psychiatric counterparts is unknown. However, interviews with neuropsychiatrists, the psychiatrists who tend to see conversion disorder most often, suggested that at least some felt that psychiatric formulation was not only possible but essential to the diagnosis, ${ }^{6}$ so that diagnosis by neurologists alone would be inappropriate. We sought to assess the views of psychiatrists on these issues by surveying them using, as far as practicable, the survey previously conducted with neurologists.

\section{Methods}

The survey was initially adapted by RAK from the previous survey, ${ }^{5}$ with questions kept as similar as possible while incorporating the results of previous interviews with neuropsychiatrists on this topic, and accommodating that it was to be surveying psychiatrists rather than neurologists. This was then sent to a panel of three international experts in FND (all consultant neurologists) for quality assurance, with their feedback and other contextual changes incorporated by consensus of the authors. The survey (see Supplementary Data) was then created on Google forms, an online survey application (www.google.com.au/forms/ about), and piloted on a sample group of medical students and lay-people to ensure ease of use and understanding. The final survey consisted of 37 questions, largely multiple choice but with some rank-order and free-text questions. These included basic demographic information and details of clinician training, then targeted understanding of conversion disorder and the models employed in clinical practice, as well as attitudes towards the role of neurologists and psychiatrists in patient care. The term "conversion disorder" was used throughout, in line with the previous survey, and no definition was provided - nor was any definition offered for the various psychiatric terms in the survey, to avoid introducing bias: though original definitions for terms such as "psychogenesis" "dissociation"11 and "conversion"2 can be found, none of these is universally adopted.

The survey was approved by the Austin Health research ethics committee, and then from the Royal Australian and New Zealand College of Psychiatrists' (RANZCP) Section of Neuropsychiatry and the United Kingdom (UK) Royal College of Psychiatrists' (RCPsych) Faculty of Neuropsychiatry, to allow distribution of the survey to their membership lists. Membership of both neuropsychiatry groups is an "opt-in" for fellows and trainees, and does (in Australia) come at a small cost. Membership of either does not require any specific training or experience, so that membership may be defined more by their interest in neuropsychiatry than clinical position or background. An email was sent from each organisation introducing the project and explaining that completing the survey implied consent to participate, and included a hyperlink leading to the online questionnaire which they completed anonymously. Approximately one month after distribution, a reminder email with another link to the survey was sent to all members, including a request not to complete the survey if they had previously done so.

Data collected were entered into and analysed with SPSS Statistics v25 (www.IBM.com). Statistical comparisons to our earlier survey were made where appropriate. P-values represent chi-squared tests unless stated otherwise, with a significance level set at 0.05 .

\section{Results \\ Demographics}

Emails were sent to the 476 members of the RANZCP Section and 4361 members of the RCPSYCH Faculty of Neuropsychiatry. Thirty-three and 96 members responded, respectively, with a further 19 and 38 members, respectively, responding in the second round. Three responses were excluded from the analysis due to duplication, but all other responses were included in the analysis as they were completed to a satisfactory degree. This gave a completion rate of 52/476 (11\%) for Australian and 131/4361 (3\%) for UK 
psychiatrists. Some respondents provided additional comments within the survey or by direct email to the authors, either about the survey design or regarding the nuances of conversion disorder.

The demographics of respondents and their clinical backgrounds are presented in Table 1. Respondents were largely male $(63 \%)$, between the ages of $31-50$, with the great majority $(83 \%)$ having trained in the United Kingdom and Australia/New Zealand, associated with the sites of survey distribution. Only $19 \%$ were employed as

Table I Demographic and Clinical Experience of Respondents with Percentages Being of Those Answering the Question, Rounded to the Nearest Whole Number

\begin{tabular}{|c|c|c|}
\hline Characteristic & \multicolumn{2}{|l|}{$\mathbf{N}(\%)$} \\
\hline Gender & \\
\hline Male & \multicolumn{2}{|l|}{$115(63)$} \\
\hline Female & \multicolumn{2}{|l|}{$68(37)$} \\
\hline Age (years) & \\
\hline$<30$ & \multicolumn{2}{|l|}{7 (4) } \\
\hline $31-40$ & \multicolumn{2}{|l|}{$55(30)$} \\
\hline $4 I-50$ & \multicolumn{2}{|l|}{$56(31)$} \\
\hline $51-60$ & \multicolumn{2}{|l|}{$39(21)$} \\
\hline$>61$ & \multicolumn{2}{|l|}{$26(14)$} \\
\hline \multicolumn{3}{|l|}{ Country of training } \\
\hline United Kingdom & \multicolumn{2}{|l|}{$115(63)$} \\
\hline Australia & \multicolumn{2}{|l|}{$32(17)$} \\
\hline India & \multicolumn{2}{|l|}{$11(6)$} \\
\hline New Zealand & \multicolumn{2}{|l|}{$6(3)$} \\
\hline Other & \multicolumn{2}{|l|}{$19(11)$} \\
\hline Specialty of employment & \multirow{5}{*}{\multicolumn{2}{|c|}{$\begin{array}{l}40(22) \\
35(19) \\
107(59) \\
1(<1)\end{array}$}} \\
\hline Liaison psychiatry & & \\
\hline Neuropsychiatry & & \\
\hline Other psychiatry & & \\
\hline Neurology & & \\
\hline Further psychodynamic training & \multirow{3}{*}{\multicolumn{2}{|c|}{$\begin{array}{l}96(52) \\
87(48)\end{array}$}} \\
\hline Yes & & \\
\hline No & & \\
\hline Experience of conversion before medicine & \multirow{6}{*}{\multicolumn{2}{|c|}{$\begin{array}{l}148(8 \mid) \\
0(0) \\
17(9) \\
13(7) \\
2(1)\end{array}$}} \\
\hline None & & \\
\hline In self & & \\
\hline In family member & & \\
\hline In friend & & \\
\hline Combination of the above & & \\
\hline Characteristic & Median & Range \\
\hline Years in psychiatry & 14 & $1-47$ \\
\hline Months in neurology & 3 & $0-60$ \\
\hline New CD cases per year & 4 & $0-200$ \\
\hline
\end{tabular}

neuropsychiatrists. This represents a markedly more female $(37 \%$ vs $17 \%, \mathrm{p}<0.0001)$ and slightly younger group (median mid 40s vs high 40s) than the neurologists from our earlier survey, though the psychiatric group included trainees, which the neurologist group did not. Based on their years of psychiatric experience (typical psychiatric training in both jurisdictions being 6 years), $15 \%$ of respondents could be expected to still be in training. The majority of respondents $(52 \%)$ had undertaken some psychodynamic training in addition to the fellowship requirement, and 52\% had undertaken some training in neurology (median 3 months), with female respondents significantly less (median 0 vs 3.5 months, $p=0.01$, Mann-Whitney $U$-test). The case load of patients presenting with conversion disorder was positively skewed, with a median of four cases seen per year, 5\% seeing none and $5 \%$ seeing a hundred or more. Eighteen percent reported having exposure to conversion disorder prior to studying, in their friends or family (most frequently their mother) nearly twice the proportion in neurology $(10 \%, \mathrm{p}=0.008)$. Previous experience of conversion disorder prior to studying medicine was not associated with specific views; however, respondents with prior exposure were more likely to elaborate on "other" options and describe clinical cases which may indicate a deeper interest in the area.

\section{The Nature of Conversion Disorder}

Responses regarding the psychiatrists' attitudes and understanding of conversion disorder are presented in Table 2. The overwhelming view was that psychogenesis was involved (94\%), usually (63\%) in combination with nervous system dysfunction (this question was not asked in the original survey of neurologists, but came from a Dutch survey, ${ }^{12}$ and our figures differ significantly from the neurologists sampled there $\left(p<0.001, \chi^{2}=22\right)$, with more of our respondents choosing psychogenesis and fewer choosing nervous system dysfunction). Accordingly, though their preferred models for understanding the disorder varied widely (Figure 1), "conversion", "abnormal illness behaviour", and "dissociation" were the most commonly accepted. Those with more experience in neurology were less likely to preference "dissociation" ( $\left.p=0.04, \chi^{2}=27\right)$ or "psychogenesis" $\left(\mathrm{p}=0.03, \chi^{2}=34.6\right)$, and female psychiatrists were more inclined towards "psychogenesis" $\left(\mathrm{p}=0.02, \chi^{2}=11.9\right)$. Most respondents felt they had a sufficient explanatory model for conversion disorder in general (in contrast with neurologists, most of whom felt psychiatrists did not), and that in an ideal scenario, with sufficient time and patient compliance, they 
Table 2 Psychiatrists' Views on the Nature of Conversion Disorder

\begin{tabular}{|c|c|}
\hline & $\mathbf{N}(\%)$ \\
\hline $\begin{array}{l}\text { Do you see the aetiology of conversion disorder as involving: } \\
\text { Disordered functioning of the nervous system } \\
\text { Psychogenesis } \\
\text { Disordered functioning of the nervous system plus } \\
\text { psychogenesis } \\
\text { Feigning } \\
\text { Unknown or other }\end{array}$ & $\begin{array}{l}3(2) \\
57(31) \\
115(63) \\
3(2) \\
5(3)\end{array}$ \\
\hline $\begin{array}{l}\text { What is the relationship of conversion disorder to feigning? } \\
\text { Overlap } \\
\text { Completely distinct } \\
\text { Feigning a subset of conversion } \\
\text { Conversion a subset of feigning }\end{array}$ & $\begin{array}{l}102(56) \\
52(28) \\
25(14) \\
3(2)\end{array}$ \\
\hline $\begin{array}{l}\text { Do you think you have a sufficient model for conversion } \\
\text { disorder in general? } \\
\text { Yes } \\
\text { No }\end{array}$ & $\begin{array}{l}103(56) \\
79(43)\end{array}$ \\
\hline $\begin{array}{l}\text { Do you think with enough time and a compliant patient, } \\
\text { a psychosocial explanation could be found for a case of } \\
\text { conversion disorder? } \\
\text { Never } \\
\text { Rarely } \\
\text { Often } \\
\text { Usually } \\
\text { Always }\end{array}$ & $\begin{array}{l}0(0) \\
12(7) \\
79(43) \\
83(45) \\
9(5)\end{array}$ \\
\hline $\begin{array}{l}\text { How often can you find a psychosocial explanation for } \\
\text { a patient's symptoms in practice? } \\
\text { Never } \\
\text { Rarely } \\
\text { Often } \\
\text { Usually } \\
\text { Always }\end{array}$ & $\begin{array}{l}1(<1) \\
14(8) \\
96(52) \\
66(36) \\
6(3)\end{array}$ \\
\hline $\begin{array}{l}\text { What proportion of your patients referred with unexplained } \\
\text { neurological symptoms do you think are feigning? } \\
\text { None } \\
\text { A few } \\
\text { Many } \\
\text { Most or all of them }\end{array}$ & $\begin{array}{l}37(20) \\
140(76) \\
3(2) \\
1(<1)\end{array}$ \\
\hline $\begin{array}{l}\text { Do you understand conversion disorder to be neurological, } \\
\text { in the same way that multiple sclerosis is neurological? } \\
\text { Yes } \\
\text { Not now, but I expect to one day } \\
\text { No, and I expect I never will }\end{array}$ & $\begin{array}{l}14(8) \\
67(37) \\
99(54)\end{array}$ \\
\hline
\end{tabular}

could (50\%) usually or always find a psychosocial explanation for a patient's presentation, though this dropped somewhat (39\%) in clinical practice. Yet, 37\% said they expected to understand it as a neurological disorder in future, in the same way as Multiple Sclerosis, much higher than the neurologists $\left(\mathrm{p}=0.03, \chi^{2}=7.3\right)$.

The relationship with feigning differed from that described by neurologists $\left(p=0.001, \chi^{2}=15.7\right.$ ), with relatively more psychiatrists seeing $\mathrm{CD}$ and feigning as overlapping concepts $(56 \%)$ and relatively fewer seeing them as completely distinct $(28 \%)$; the proportion of their patients they believed to be feigning was significantly less than the proportion reported by the neurologists $\left(p<0.001, \chi^{2}=47.5\right.$ ).

Eighty-four respondents described a memorable case, and the same qualitative judgement as in the neurologists' survey was made by the same author (RAK) about what was distinctive about those cases. Thirty-seven of them fit the categories previously reported, with 19 appearing to be "classic" cases where the formulation made sense of the symptoms, and 16 "dramatic", where the symptoms or circumstances were unusual, such as a functional blindness; none fit the category of "deception", significantly fewer than the neurologists ( $p=0.02$, Fisher's Exact Test), though two did mention apparent secondary gain. Distinctive features for many cases (but not considered categories in the neurologists' study, and therefore not included in the comparison above) appeared to be the outcomes or responses to treatment, or of particular comorbidity, notably psychosis and intellectual disability.

\section{Diagnosing Conversion Disorder}

Responses to questions regarding the diagnostic process are presented in Table 3. There was some evidence of wariness of neurologists' diagnoses, and of confidence in psychiatrists' own role and skills. Nearly two-thirds $(63 \%)$ said they felt psychiatrists were essential to the diagnosis, and none that they were unhelpful, a markedly more positive view than neurologists held $\left(\mathrm{p}<0.001, \chi^{2}=67.6\right)$. In support of this, $81 \%$ said they at least sometimes sent referrals back to the neurologist because the patient did not have a psychiatric disorder (more commonly in the UK ( $\mathrm{p}=0.04$, $\left.\chi^{2}=10.3\right)$ ), and a third (32\%) said they often or very often diagnosed the referred patient with a different psychiatric disorder instead. Most felt a neurologist was important to the diagnosis; however, with only a minority (80 participants, $44 \%$ ) reporting confidence they could make the diagnosis without one often or usually, and none that they could do so always (this confidence, surprisingly, did not vary with experience in neurology, the number of cases seen or the specialty of employment). But they still saw the psychiatric role as necessary: even if the neurologist was certain of the diagnosis, only $24 \%$ would agree if they could not formulate 


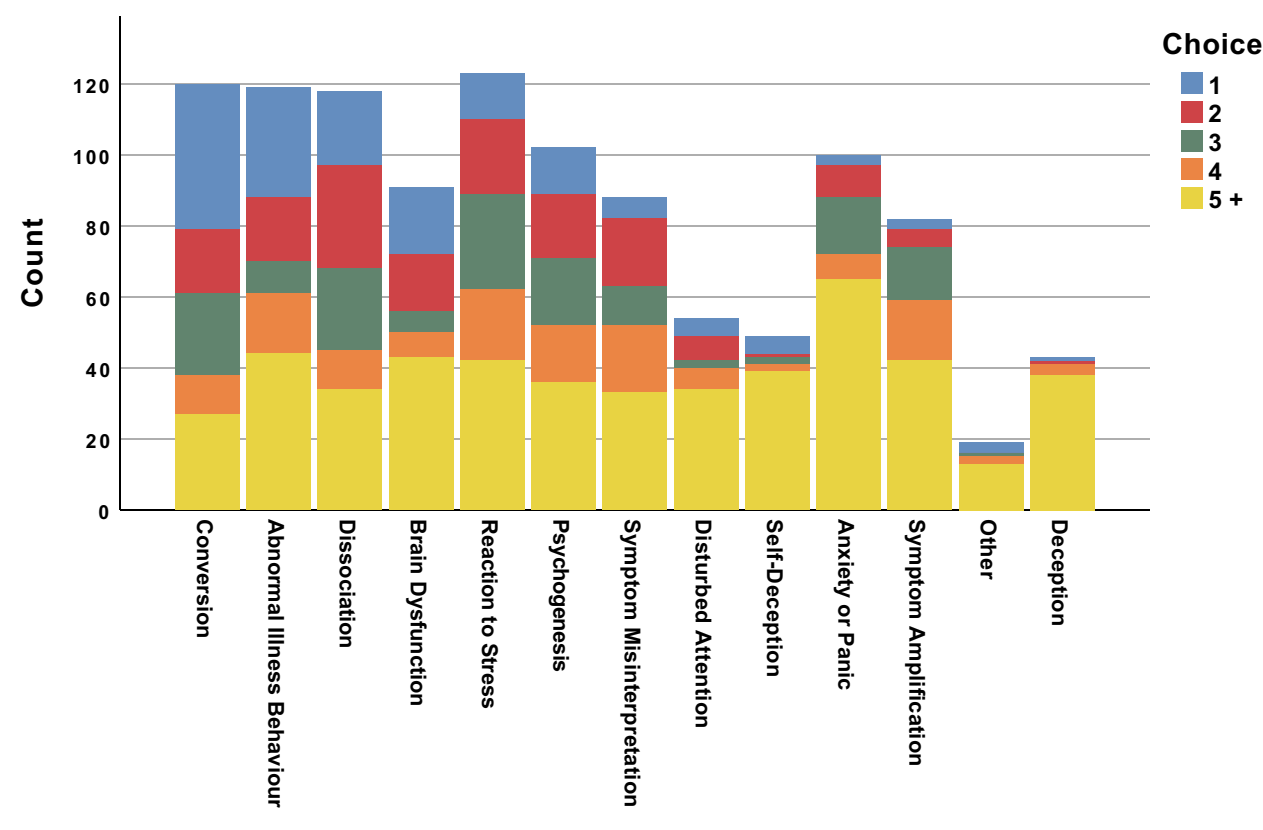

Model

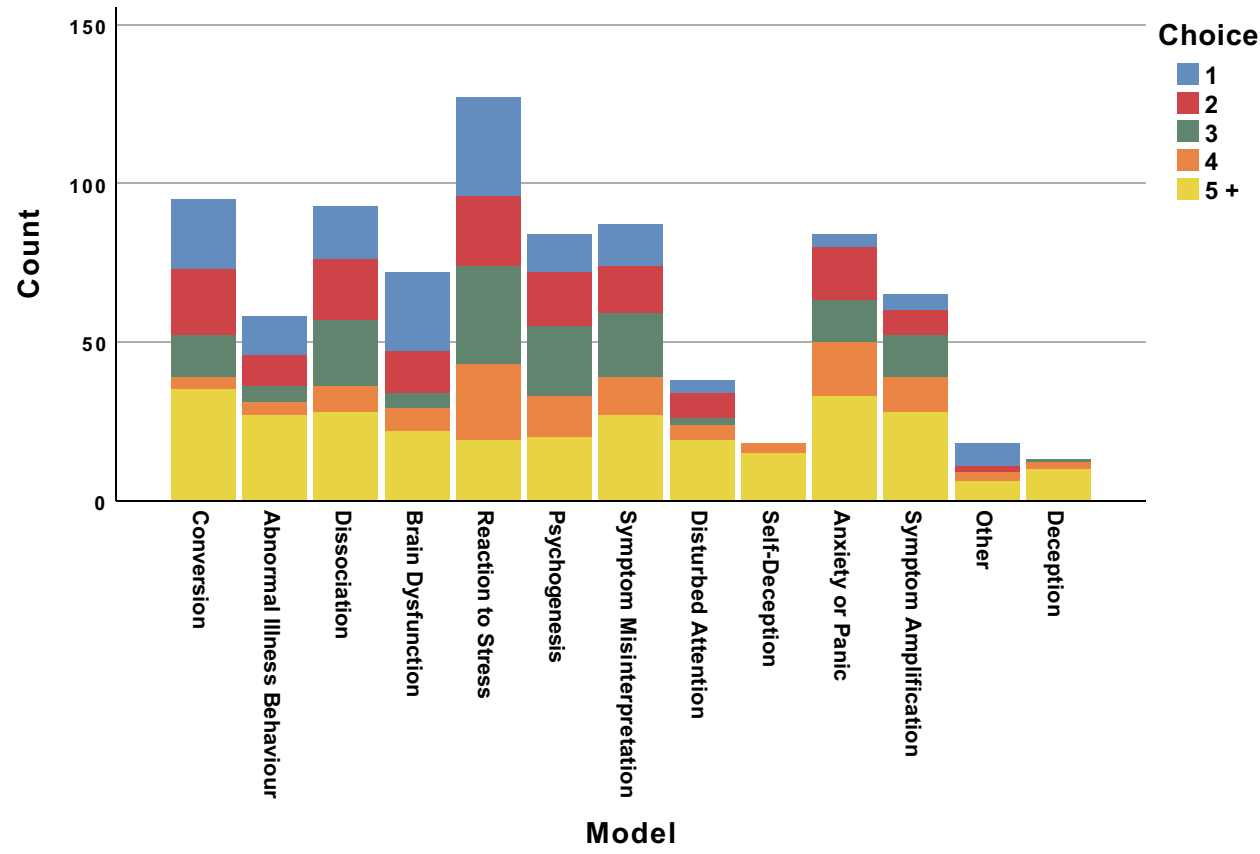

Figure I Psychiatrists' preferred model for understanding (top) and explaining (bottom) conversion disorder. Respondents answered these questions via rank order from I to I3, where a characteristic marked "I" was considered most important and "I3" to be least important.

the patient's problem themselves; by contrast, where the neurologist was unsure, the majority of psychiatrists $(58 \%)$ would make the diagnosis if they could find an explanation for the patients' problem themselves. None of these attitudes differed with the age or sub-specialty of employment of the psychiatrist, or the number of patients with conversion disorder they saw, though, perhaps surprisingly, those with additional psychodynamic training were less likely to make the diagnosis when the neurologist was unsure $(\mathrm{p}=0.05$, $\left.\chi^{2}=7.9\right)$.

\section{Communicating with Patients and Colleagues}

Views of the psychiatrists on communicating with patients and colleagues can be seen in Table 4 and Figures 1 and 2. Figure 1 shows the discordance between 
Table 3 Psychiatrists' Views on the Diagnosis of Conversion Disorder

\begin{tabular}{|c|c|}
\hline & $\mathbf{N}(\%)$ \\
\hline $\begin{array}{l}\text { If a referring neurologist is sure that a patient has } \\
\text { conversion disorder but you cannot explain their } \\
\text { symptoms, would you make the diagnosis? } \\
\text { Yes } \\
\text { Depends on the neurologist } \\
\text { No }\end{array}$ & $\begin{array}{l}44(24) \\
65(36) \\
73(40)\end{array}$ \\
\hline $\begin{array}{l}\text { What role do psychiatrists have in the diagnosis of } \\
\text { conversion disorder? } \\
\text { Not helpful } \\
\text { Helpful, but not essential } \\
\text { Essential }\end{array}$ & $\begin{array}{l}0(0) \\
66(36) \\
116(63)\end{array}$ \\
\hline $\begin{array}{l}\text { If a referring neurologist is not sure of the diagnosis, but } \\
\text { you can find an explanation, would you make the } \\
\text { diagnosis? } \\
\text { Yes } \\
\text { Depends on the neurologist } \\
\text { No }\end{array}$ & $\begin{array}{l}107(58) \\
39(21) \\
34(19)\end{array}$ \\
\hline $\begin{array}{l}\text { How often do you send conversion disorder referrals } \\
\text { back to neurologists because you do not think the patient } \\
\text { has a psychiatric disorder? } \\
\text { Never } \\
\text { Rarely } \\
\text { Often } \\
\text { Very often }\end{array}$ & $\begin{array}{l}35(19) \\
115(63) \\
30(16) \\
I(<1)\end{array}$ \\
\hline $\begin{array}{l}\text { How often do you diagnose a conversion disorder } \\
\text { referral with a different psychiatric disorder instead? } \\
\text { Never } \\
\text { Rarely } \\
\text { Often } \\
\text { Very often }\end{array}$ & $\begin{array}{l}10(5) \\
110(60) \\
57(31) \\
2(1)\end{array}$ \\
\hline $\begin{array}{l}\text { Would you be confident in diagnosing a case of } \\
\text { conversion disorder without assessment by a neurologist? } \\
\text { Never } \\
\text { Rarely } \\
\text { Often } \\
\text { Usually } \\
\text { Always }\end{array}$ & $\begin{array}{l}26(14) \\
77(42) \\
46(25) \\
34(19) \\
0(0)\end{array}$ \\
\hline
\end{tabular}

models used in understanding and explaining the disorder. The clear favourite as a model for understanding the condition, "conversion" (1st choice for 41, 22\%), drops to the third most popular for explaining the condition (1st choice for 22, 12\%); while "reaction to stress", the 5th most popular choice for understanding the condition (1st choice for $13,7 \%$ ), is the most popular way to explain it (1st choice for $31,17 \%$ ). In terms of terminology, there
Table 4 Psychiatrists' Views on Communicating with Patients About Conversion Disorder and Feigning

\begin{tabular}{|c|c|}
\hline & $\mathbf{N}(\%)$ \\
\hline $\begin{array}{l}\text { Do you copy letters about your conversion patients to } \\
\text { them? }\end{array}$ & \\
\hline Never & $27(15)$ \\
\hline Rarely & $45(25)$ \\
\hline Often & $33(18)$ \\
\hline Usually & $4 \mid(22)$ \\
\hline Always & $33(18)$ \\
\hline $\begin{array}{l}\text { Is it important to distinguish feigning from conversion } \\
\text { disorder? }\end{array}$ & \\
\hline Yes & $159(87)$ \\
\hline No & $22(12)$ \\
\hline Who should address feigning in your patient? & \\
\hline $\mathrm{Me}$ & $45(25)$ \\
\hline General practitioner & $4(2)$ \\
\hline Neurologist & $5(3)$ \\
\hline Police or some other agency & $14(8)$ \\
\hline No-one & $10(5)$ \\
\hline Combination of the above & $99(57)$ \\
\hline $\begin{array}{l}\text { What role do psychiatrists have in the management of } \\
\text { conversion disorder? }\end{array}$ & \\
\hline Not helpful & $0(0)$ \\
\hline Helpful, but not essential & $56(31)$ \\
\hline Essential & $123(67)$ \\
\hline $\begin{array}{l}\text { Do you talk about feigning with patients with unexplained } \\
\text { neurology if you suspect it? }\end{array}$ & \\
\hline Never & $40(22)$ \\
\hline Rarely & $80(44)$ \\
\hline Usually & $56(31)$ \\
\hline Always & $6(3)$ \\
\hline $\begin{array}{l}\text { Do you talk about feigning with patients with unexplained } \\
\text { neurology if you are sure of it? }\end{array}$ & \\
\hline Never & $25(14)$ \\
\hline Rarely & $56(3 \mathrm{I})$ \\
\hline Usually & $74(40)$ \\
\hline Always & $25(14)$ \\
\hline $\begin{array}{l}\text { Do you talk about feigning with patients with unexplained } \\
\text { neurology when you do not suspect it? }\end{array}$ & \\
\hline Never & $116(63)$ \\
\hline Rarely & $49(27)$ \\
\hline Usually & $10(5)$ \\
\hline Always & $3(2)$ \\
\hline
\end{tabular}

was less of a shift (Figure 2): though "conversion disorder" was the most used term (by 140, 77\%), "functional neurological disorder" was the single most popular choice for speaking to colleagues (1st choice for 57, 31\%) and 

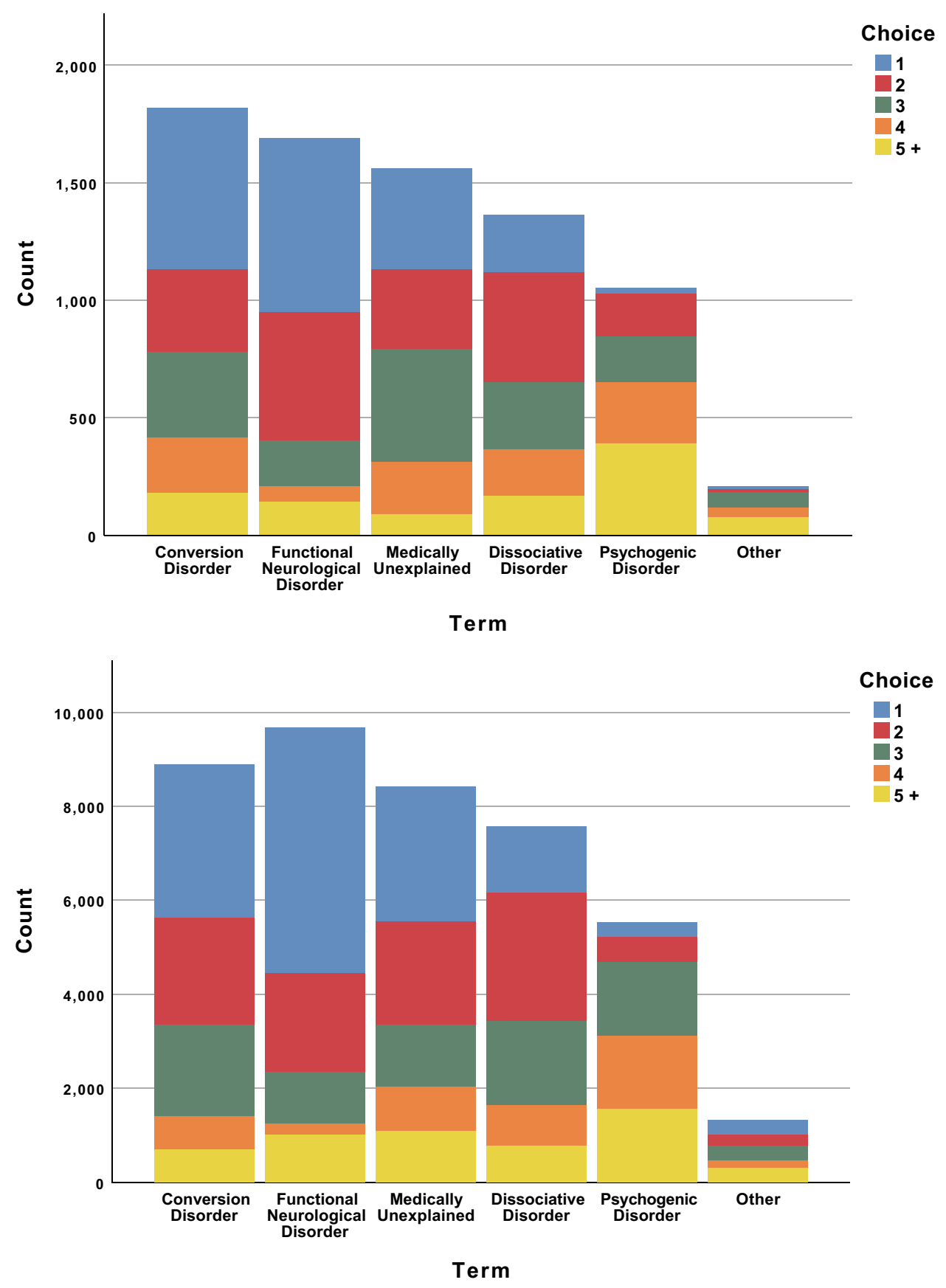

Figure 2 Psychiatrists' preferred terminology to use with colleagues (top) and patients (bottom). Respondents answered these questions via rank order from I-6, where a characteristic marked "I" was considered most important and " 6 " to be least important.

even more popular for speaking to patients (1st choice for $67,37 \%)$.

Only a minority (40\%) always or usually sent copies of their letters to patients - a surprisingly low figure, given that this is an expectation for all patients in the UK, though UK psychiatrists did do so more frequently $\left(\mathrm{p}<0.001, \chi^{2}=26.3\right)$.

A significant majority (87\%) identified the need to differentiate feigning from conversion disorder in clinical practice, particularly older psychiatrists $\left(\mathrm{p}=0.05, \quad \chi^{2}=\right.$ 15.8). Perhaps consequently, feigning was more confidently, or at least more frequently, addressed by the psychiatrists than neurologists. Even when feigning was not suspected, $7 \%$ said they would talk about it usually or always; when there was a degree of suspicion, 34\% would; when confident, $54 \%$ would - far more than their neurological colleagues $\left(p<0.001, \chi^{2}=30.4\right)$ 


\section{Discussion}

Psychiatrists strongly endorsed psychological models for conversion disorder, and the conversion model in particular, though many models were employed. They felt a psychiatric assessment was essential to the diagnosis of conversion disorder, and that they often disagreed with the diagnosis in neurologists' referrals of putative conversion disorder. Most felt that a psychiatric formulation was supportive of, and many that it was necessary for, a diagnosis. Though few thought of conversion disorder as feigning, most saw these as overlapping concepts and they felt more comfortable discussing this than the neurologists previously surveyed.

The differences from the neurologists were perhaps less striking than might have been expected, given the divergent stereotypes with which the specialties are portrayed. There were notable similarities: the psychiatrists also saw conversion disorder as psychogenic rather than neurological; they also largely saw conversion disorder and feigning as overlapping but not the same; they also did not freely talk about feigning when they suspected it. Yet many differences, of degree, stood out: psychiatrists were stronger in their support of psychogenesis; less likely to think of deception when they thought of a memorable case; more confident in their ability to understand and formulate a patient psychosocially. But perhaps most striking were their views on the role of psychiatrists in diagnosis, and on the diagnostic relationship with neurology. Psychiatrists felt they were essential to the diagnostic process: they reported quite frequently sending patients back to neurologists because they believed the neurologist had got the diagnosis of conversion disorder wrong, a result which evokes psychiatrist Eliot Slater's infamous claim that the diagnosis of "hysteria" represented systematic misdiagnosis by incompetent neurologists. ${ }^{13}$ Widespread psychiatric disagreement with neurologists' diagnoses of conversion disorder has been reported more recently than that, from the neurologist perspective, ${ }^{6}$ and not only by us. ${ }^{14}$ But though from the point of view of neurologists this disagreement appears to be psychiatric error, ${ }^{14}$ it appears just as clearly, from these psychiatrists' perspective, to be error by neurologists. Psychiatrists reported they were sending patients back not because they had overlooked conversion disorder, as neurologists strongly believed, ${ }^{14}$ but because they did not think conversion disorder was the right psychiatric diagnosis. Moreover, psychiatrists reported they would not, in general, accept the diagnosis without the presence of a formulation. Diagnoses made on neurological grounds, however confidently, were more likely to be rejected than accepted as conversion disorder, and a psychiatric formulation was clearly seen as diagnostic proof when there was neurological doubt. In both questions, large minorities thought a neurologist's opinion could be decisive - but not all neurologists' opinions.

Though the validity of the DSM-5 diagnostic criteria was not the subject of this survey directly, these results appear to raise significant doubts about psychiatric support for them. As this is the first survey of its kind that we are aware of, and the DSM field testing did not include conversion disorder, ${ }^{15}$ psychiatrists' views are unlikely to have been taken into account in any systematic way. The new criteria are commonly interpreted as saying the diagnosis is now "inclusionary", on the basis of its neurological signs alone, ${ }^{16}$ but this survey suggests psychiatrists do not agree. As they usually do not feel confident in diagnosing conversion disorder themselves, and do not feel confident that a neurologist can do so alone, this suggests support for the "old" two-step process, with assessment by a neurologist followed by diagnosis by a psychiatrist. Psychiatrists may, of course, simply be being conservative in this - though there was no association of these attitudes with age or experience, the changes are relatively new and the respondents may not have been familiar with them. As a group with a particular interest in neuropsychiatry, however, and who are seeing patients with conversion disorder with some regularity this seems less likely. Perhaps they are merely "protecting their turf", and resisting further inroads into their prerogatives? Their reported diagnostic disagreements suggest they at least believe they have clinical reasons for doing so. Some of these reasons may be the less controversial role of psychiatrists in management of conversion disorder, and the importance of psychiatric formulation to that $\mathrm{end}^{17}$ - perhaps one interpretation of their response is that a diagnosis without formulation may be possible, but unwise.

Psychiatrists seem to have embraced some recent changes more than others. The term "Functional Neurological Disorder" is now the most frequently used diagnosis with patients but most still explain this in terms of psychogenic aetiology, notably as a "reaction to stress". Though they perhaps did not differ starkly from neurologists on their attitudes to feigning, psychiatrists appeared less troubled by it and more willing to see it as part of a spectrum, always present. ${ }^{18}$ This suggests that the other 
major change in DSM-5 - dropping the requirement to specifically exclude feigning - would be supported by these respondents; indeed, their relative ease may suggest they have already adopted the change. On the other hand, it might also suggest that the two-stage process would be preferred, at least when feigning was a significant element, as the psychiatrists appear to feel much more comfortable discussing feigning than their neurological colleagues.

\section{Limitations}

Any survey inherently introduces bias in shaping the way that answers are obtained, limiting the choices to predefined criteria and suggesting answers which may not have otherwise been considered. The use of multiple-choice questions may force the respondent to choose an option which may not exactly align with their beliefs; however, we used free text questions when possible to allow the individual to propose other ideas, most obviously in the "memorable case". As no definition was given for the term "conversion disorder", respondents will have depended on their own understanding of the condition, and the term "conversion" may have impelled respondents towards traditional interpretations; however, as the official psychiatric term for the disorder, this is less likely to have introduced any novelty than it was for the neurologists, and the provision of a definition could have introduced even more significant bias. Equally, terms such as "dissociation" and "psychogenesis" are notably ambiguous, ${ }^{10,19}$ which limits our interpretation of respondents' views on these, but an attempt at acceptable definitions for these is an undertaking beyond the scope of this survey and would introduce bias of its own.

The use of an internet-based survey distribution for sampling may have also introduced bias, favouring younger or urban respondents. It probably contributed to the markedly reduced response rate compared with our paper survey of the neurologists, so the sample would inevitably be more restricted and more biased, presumably to those with the keenest interest, and perhaps the strongest opinions; the reduced response may also reflect a relative lack of interest within the specialty. All were drawn from groups defined by an interest in neuropsychiatry, though most did not work as neuropsychiatrists - and at median 4 cases per year, were not seeing very large numbers of patients with conversion disorder. While, on the one hand, this broadens the generalisability of these views beyond specialists, it also dilutes any claim to specific expertise in the area.
We sampled two countries, which clearly strengthens validity and generalisability, though those two countries are strongly linked by national and medical culture - and there were very few response differences between the two samples. By contrast, however, the survey of neurologists was of UK consultants only, so the comparison is limited thereby, as well as by elements of the survey process, though these did not appear to materially affect the neurologists' responses. ${ }^{20}$ That survey was conducted in 2009 , some 10 years prior to this one, so neurologists' attitudes may well have changed, and that survey should be repeated.

Above all, these are survey data, and reflect what respondents think or remember about their behaviour, and their actual behaviour, for example, of disagreement with neurologists, may be very different.

\section{Conclusion}

Psychiatrists believe conversion disorder to be psychogenic and to overlap with feigning. They believe psychiatrists are essential for the diagnostic process and would not usually support a diagnosis without a psychiatric formulation.

\section{Data Sharing Statement}

No additional data are available.

\section{Author Contributions}

RK designed the study, analysed the data, edited the manuscript and acts as guarantor; BD designed the study, collected the data, analysed the data, and drafted the manuscript; BS designed the study and edited the manuscript. All authors had full access to all of the data in the study and can take responsibility for the integrity of the data and the accuracy of the data analysis. All authors approved the final manuscript.

\section{Funding}

This study was partly funded by a Biomedical Ethics Fellowship 079743 from the Wellcome Trust. The funders had no role in the design, execution, analysis or writing of this study.

\section{Disclosure}

All authors have completed the Unified Competing Interest form at www.icmje.org/coi disclosure.pdf (available on request from the corresponding author) and declare that (1) RK had support from The Wellcome Trust for the 
submitted work; (2) no authors have relationships with companies that might have an interest in the submitted work in the previous 3 years; (3) their spouses, partners, or children have no financial relationships that may be relevant to the submitted work; and (4) the authors have no non-financial interests that may be relevant to the submitted work.

\section{References}

1. Nicholson TR, Stone J, Kanaan RA. Conversion disorder: a problematic diagnosis. J Neurol Neurosurg Psychiatry. 2011;82 (11):1267-1273. doi:10.1136/jnnp.2008.171306

2. Breuer J, Freud S. Studies in Hysteria. In: Freud S, Strachey J, Freud A, Rothgeb CL, Richards A, editors. The Standard Edition of the Complete Psychological Works of Sigmund Freud. Vol. II. London: Hogarth Press; 1895.

3. Kanaan R, Armstrong D, Barnes P, Wessely S. In the psychiatrist's chair: how neurologists understand conversion disorder. Brain. 2009;132(Pt 10):2889-2896. doi:10.1093/brain/awp060

4. Kanaan R, Armstrong D, Wessely S. Limits to truth-telling: neurologists' communication in conversion disorder. Patient Educ Couns. 2009;77(2):296-301. doi:10.1016/j.pec.2009.05.021

5. Kanaan RA, Armstrong D, Wessely SC. Neurologists' understanding and management of conversion disorder. J Neurol Neurosurg Psychiatry. 2011;82(9):961-966. doi:10.1136/jnnp.2010.233114

6. Kanaan RA, Armstrong D, Wessely S. The role of psychiatrists in diagnosing conversion disorder: a mixed-methods analysis. Neuropsychiatr Dis Treat. 2016;12:1181-1184. doi:10.2147/NDT. S96330

7. American Psychiatric Association, American Psychiatric Association. DSM-5 Task Force. Diagnostic and Statistical Manual of Mental Disorders: DSM-5. 5th ed. Washington, D.C.: American Psychiatric Association; 2013.

8. Kanaan RAA, Craig TKJ. Conversion disorder and the trouble with trauma. Psychol Med. 2019;49(10):1585-1588. doi:10.1017/S003329 1719000990
9. WHO. ICD-11: International Statistical Classification of Disease and Related Health Problems: Eleventh Revision. World Health Organisation; 2018.

10. Lewis A. 'Psychogenic': a word and its mutations. Psychol Med. 1972;2(3):209-215. doi:10.1017/S0033291700042501

11. Janet P. The Major Symptoms of Hysteria: Fifteen Lectures Given in the Medical School of Harvard University. New York: Macmillan Co.; 1907:345.

12. de Schipper LJ, Vermeulen M, Eeckhout AM, Foncke EM. Diagnosis and management of functional neurological symptoms: the Dutch experience. Clin Neurol Neurosurg. 2014;122:106-112. doi:10.10 16/j.clineuro.2014.04.020

13. Stone J, Smyth R, Carson A, et al. Systematic review of misdiagnosis of conversion symptoms and "hysteria". BMJ. 2005;331(7523):989. doi:10.1136/bmj.38628.466898.55

14. Espay AJ, Goldenhar LM, Voon V, Schrag A, Burton N, Lang AE. Opinions and clinical practices related to diagnosing and managing patients with psychogenic movement disorders: an international survey of movement disorder society members. Mov Disord. 2009;24 (9):1366-1374. doi:10.1002/mds.22618

15. Regier DA, Narrow WE, Clarke DE, et al. DSM-5 field trials in the United States and Canada, Part II: test-retest reliability of selected categorical diagnoses. Am $J$ Psychiatry. 2013;170(1):59-70. doi:10.1176/appi.ajp.2012.12070999

16. Espay AJ, Aybek S, Carson A, et al. Current concepts in diagnosis and treatment of functional neurological disorders. JAMA Neurol. 2018;75(9):1132-1141. doi:10.1001/jamaneurol.2018.1264

17. Adams C, Anderson J, Madva EN, LaFrance WC Jr., Perez DL. You've made the diagnosis of functional neurological disorder: now what? Pract Neurol. 2018;18(4):323-330. doi:10.1136/practneurol2017-001835

18. Kanaan RA, Wessely SC. The origins of factitious disorder. Hist Human Sci. 2010;23(2):68-85. doi:10.1177/0952695109357128

19. Brown RJ. Different types of "dissociation" have different psychological mechanisms. J Trauma Dissociation. 2006;7(4):7-28. doi:10. 1300/J229v07n04_02

20. Kanaan RA, Wessely SC, Armstrong D. Differential effects of pre and post-payment on neurologists' response rates to a postal survey. BMC Neurol. 2010;10:100. doi:10.1186/1471-2377-10-100
Neuropsychiatric Disease and Treatment

\section{Publish your work in this journal}

Neuropsychiatric Disease and Treatment is an international, peerreviewed journal of clinical therapeutics and pharmacology focusing on concise rapid reporting of clinical or pre-clinical studies on a range of neuropsychiatric and neurological disorders. This journal is indexed on PubMed Central, the 'PsycINFO' database and CAS, and is the official journal of The International Neuropsychiatric Association (INA). The manuscript management system is completely online and includes a very quick and fair peer-review system, which is all easy to use. Visit http://www.dovepress.com/testimonials.php to read real quotes from published authors. 